Supporting Information

\title{
Dynamically Stable Helices of Poly( $N$-propargylamides) with Bulky Aliphatic Groups
}

Jianping Deng, Junichi Tabei, Masashi Shiotsuki, Fumio Sanda,

\begin{abstract}
Toshio Masuda ${ }^{*}$
Department of Polymer Chemistry, Graduate School of Engineering, Kyoto University,
\end{abstract}

Kyoto 615-8510, Japan 
Table S1. Solubility of poly(9)-poly $(13)^{a}$

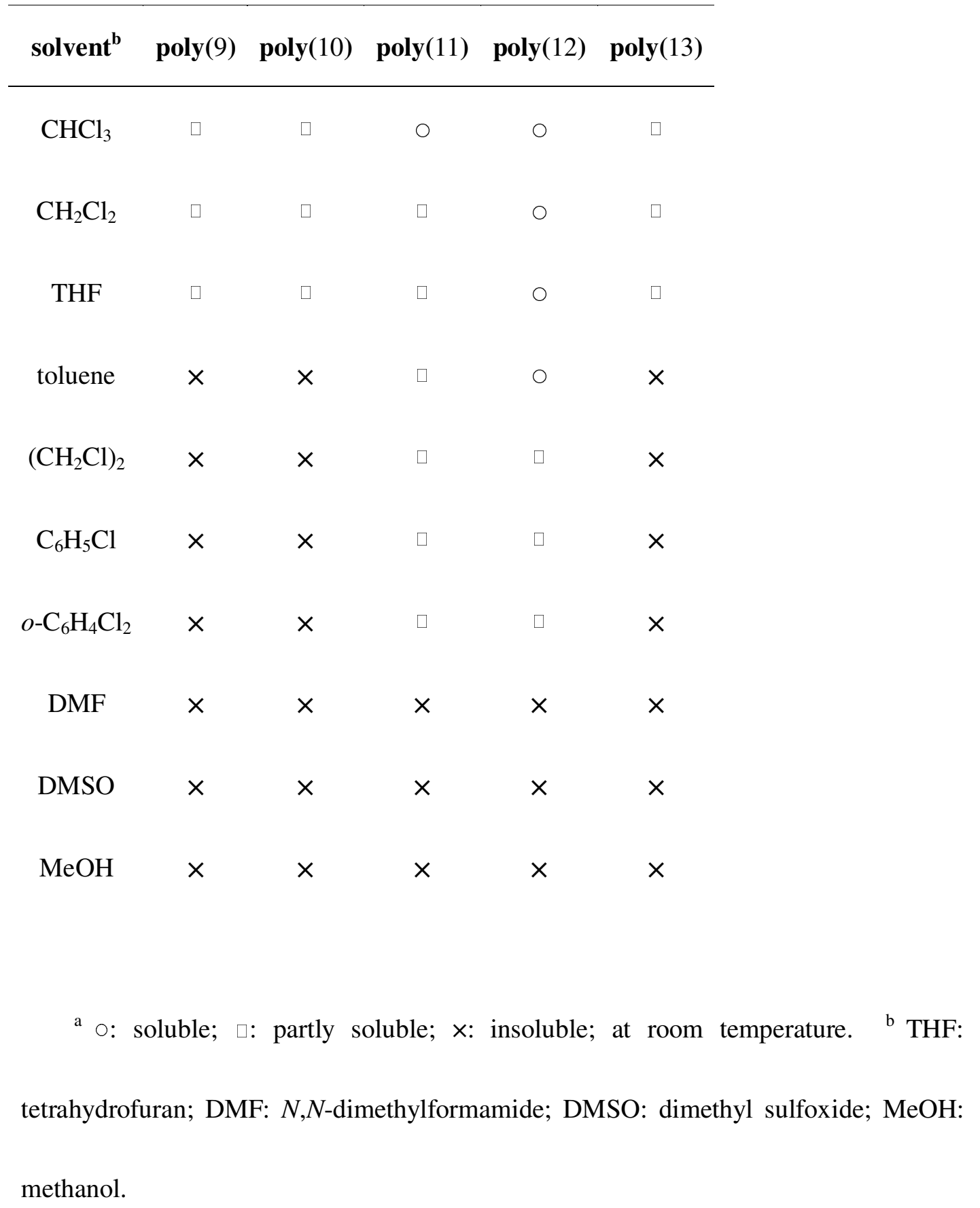


Scheme S1
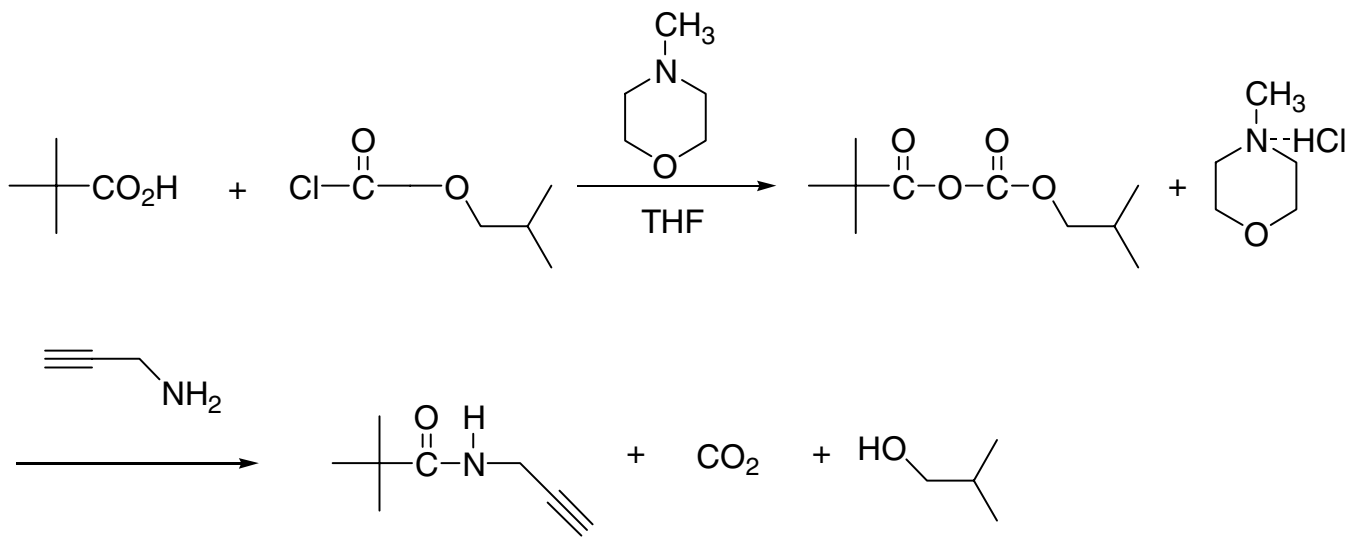

10

3 


\section{Scheme S2}
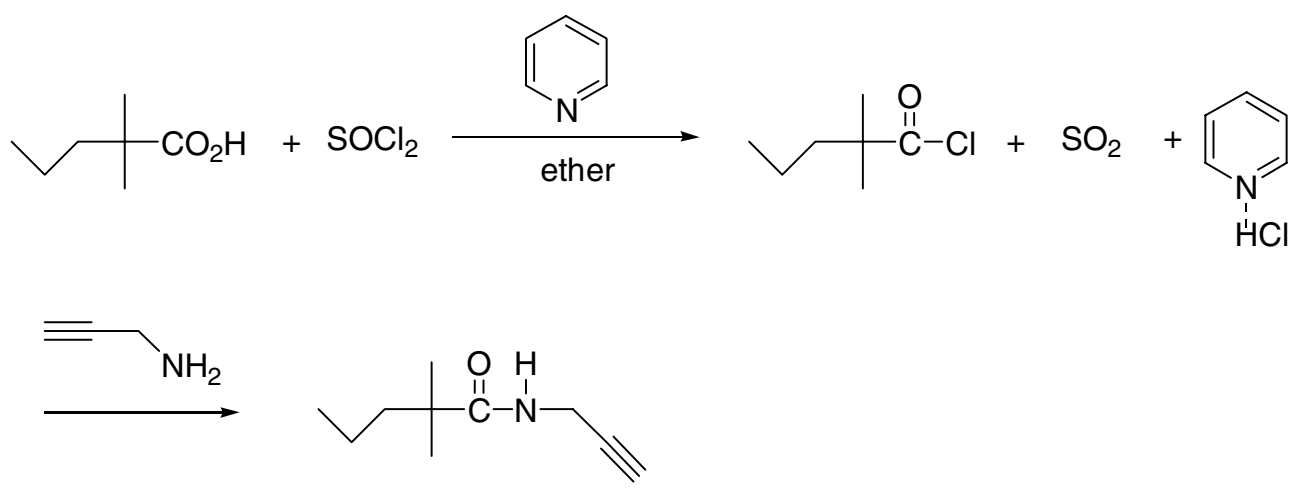

11 